\title{
Molecular Structure Changes of Rat's Retina After Sodium Iodate Injection and the Effect of Taurine
}

\author{
M.I. El Gohary ${ }^{1}$, E.M. Aly ${ }^{2}$ and A.E. Malash ${ }^{1^{*}}$ \\ ${ }^{1}$ Physics Department, Biophysics Branch, Faculty of Science, Al-Azhar \\ University (Boys), Cairo, ${ }^{2}$ Biophysics\&Laser Science Unit, Research \\ Institute of Ophthalmology, Giza, Egypt.
}

\begin{abstract}
$\mathbf{T}$ HE aim of present work is to investigate the mechanism of action of sodium iodate $\left(\mathrm{NaIO}_{3}\right)$ on the molecular structure of retina and whether the nutritional intake of taurine may delay the development of age macular degeneration (AMD) disease induced by $\mathrm{NaIO}_{3}$ using Fourier Transform Infrared spectroscopy (FTIR). One hundred and five albino rats of both sex (200-230 g) Were classified into three groups. Group I (15 rats) used as control, group II (45 rats) received a single intravenous injection of 25,50 , or $75 \mathrm{mg} / \mathrm{kg} \mathrm{NaIO}$, and group III (45 rats) supplemented with $4 \mathrm{~g}$ taurine $/ 100 \mathrm{~g}$ diet for two weeks before injection of $\mathrm{NaIO}_{3}$. The injection continued until decapitation. All injected doses of $\mathrm{NaIO}_{3}$ are associated with vibrational changes that include decrement of the modes of vibration related to stretching $\mathrm{OH}$ and amide II, significant increases $(\mathrm{p}<0.05)$ in wavenumber and width of asymmetrical $\mathrm{OH}$ and disappear of asymmetrical $\mathrm{NH}_{3}$. Also, there are significant diminish $(\mathrm{p}<0.05)$ in $\alpha$-helix content in the same context, in addition to significant increments $(\mathrm{p}<0.05)$ in $\beta$-Sheet indicating the conformational changes of the secondary structure of protein due to $\mathrm{NaIO}_{3}$ injection. Enhancement of most changes that previously detected in FTIR spectra is noticed after taurine treatment especially before and after low dose of $\mathrm{NaIO}_{3} . \mathrm{NaIO}_{3}$ is considered to be specific for animal model as age macular degeneration. Taurine action is efficient as antioxidant to protect retina from oxidative stress limits in range of $25 \mathrm{mg}$ of $\mathrm{NaIO}_{3}$ and decreases the efficiency by increasing the dose of $\mathrm{NaIO}_{3}$ up to $75 \mathrm{mg}$.
\end{abstract}

Keywords: Age macular degeneration (AMD), Retina, FTIR, Antioxidant.

\section{Introduction}

Retinal degeneration, a feature of neurodegenerative diseases such as AMD that characterize by degeneration of the macular section of the retina can lead to strict visual injury and finally blindness. Millions of people worldwide suffer varying degrees of permanent vision loss because of these not curable, as degenerative eye disorders ${ }^{(1,2)}$. There are several risk factors, including age, race, smoking, and $\operatorname{diet}^{(3)}$. But the etiology and pathogenesis of the disease remain largely unclear. Vital advances in the understanding of AMD pathogenesis have been paying attention to the role of oxidative stress (OS) or damage into the retina. It is clearly established that reactive oxygen species (ROS) and oxidized lipoproteins are crucial sources of cell and tissue stress creating enough background for parainflammation in the aging retina. This persistent situation lead to the development and/ or progression of $\mathrm{AMD}^{(4)}$. Oxidative stress results from the imbalance between the prooxidants and the antioxidant resistance leading to cellular damage.

Sodium iodate $\left(\mathrm{NaIO}_{3}\right)$ injection has been extensively used as a pre-clinical model of $\mathrm{AMD}^{(5,6)} \cdot \mathrm{NaIO}_{3}$ is directly affecting the retinal pigment epithelial (RPE) cells with resultant effects on photoreceptors and the choriocapillaris and has been shown to induce the production of reactive oxygen species causative to damages in retinal cells ${ }^{(7,8)}$.

Taurine or 2-aminoethanesulfonic acid is a derivative of cysteine, an amino acid which

\footnotetext{
*Corresponding author :ahmedmalash71@yahoo.com DOI :10.21608/ejbbe.2018.3898.1019

C2018 Nathional Information and Documentaion Center (NIDOC)
} 
contains a sulfhydryl group. Taurine antioxidant activity has been shown to play role as a cytoprotectant and in the attenuation of apoptosis. There is a growing consensus that oxidative stress is linked to mitochondrial dysfunction ${ }^{(9,10)}$, and that the beneficial effects of taurine are a result of its antioxidant properties ${ }^{(11,12)}$, as well as its ability to improve mitochondrial function by stabilizing the electron transport chain and inhibiting the generation of reactive oxygen species $^{(13)}$.

To understand the molecular mechanisms structure of disease induction and progression for retina, and to develop therapeutic strategies for vision preservation, the present study evaluates the action of $\mathrm{NaIO}_{3}$ that a model can already serve as tool to investigate beneficial effects of experimental treatments on the molecular structure of the retina and whether the dietary intake of taurine can help as an antioxidant to retina or may delay the progression of AMD.

\section{Materials and Methods}

\section{Experimental Animals}

One hundred and five albino rats of both sexes, weighing 200-230 g were randomly selected from the animal house facility at the research institute of ophthalmology, Giza, Egypt. The rats were maintained in standard $12 \mathrm{hr}$ light-dark cycle with free access to water and balanced diet at a temperature of $22 \pm 2{ }^{\circ} \mathrm{C}, 50 \%$ humidity, and kept separately under good ventilation. Animals were handled according to the Association for Research in Vision and Ophthalmology ( ARVO ) statements and regulations for the use of animals in research. The rats were classified into 3 groups I, II and III according to the following: Group I: contains 15 rats were used as control and receive intravenous injection of saline. Group II: contains 45 rats and were subdivided into 3 subgroups (15 rats each). All subgroups receive a single intravenous injection of 25, 50, or $75 \mathrm{mg} / \mathrm{kg} \mathrm{NaIO}_{3}^{(14)}$. Group III: contains 45 rats and were subdivided into 3 subgroups (15 rats each). All rats are supplemented with $4 \mathrm{~g}$ taurine $/ 100 \mathrm{~g}$ diet 2 weeks before intravenous injection of $\mathrm{NaIO}_{3}^{(15)}$. Taurine supplementation is continued until decapitation. All groups were decapitated after 1 day of $\mathrm{NaIO}_{3}$ injection.

\section{Preparation of samples}

The albino rats were sacrificed by decapitation, where the eyes were enucleated, and then opened by corneal section through the ora serrata. After removing the corneas, the iris was pulled out by a forceps where the eye lens and the vitreous humour (jelly structure) were jointly removed. The reaming eye cub, which contains the retina, removed to a previously sterilized and weighted dark brown glass vials. The glass vials were flushed by dry $\mathrm{N}_{2}$ gas and kept at $-20^{\circ} \mathrm{C}$ for FTIR measurements.

\section{FTIR Spectrophotometer measurements}

Weighted retinae were freeze-dried separately and mixed with $\mathrm{KBr}$ powder $(2 \mathrm{mg}$ retina: $98 \mathrm{mg} \mathrm{KBr}$ ) then hard-pressed to prepare the transparent $\mathrm{KBr}$ disks that will be used for the FTIR investigations. Using NicoletiS5 infrared spectrometer (ThermoFisher Scientific Inc, Madison, USA) with resolution of $2 \mathrm{~cm}^{-1}$, spectrum is derived from 100 sample interferogram. The spectrometer operation was done under a continuous dry $\mathrm{N}_{2}$ gas to remove interference from atmospheric $\mathrm{CO}_{2}$ and $\mathrm{H}_{2} \mathrm{O}$ vapor. Spectra baseline are corrected, and then smoothed with Savitsky-Golay filter. The average of three spectra using OriginPro9 software (Origin Lab Corporation, Northampton, MA, USA) is normalized according to obtain the definite peaks ${ }^{(16)}$.

\section{Statistical analysis}

Mean standard deviations are expressed through statistical analysis. Comparisons among multiple groups are made by using analysis of variance (ANOVA). Available statistical software package (SPSS-11, Windows) was used and the significance level is established at $\mathrm{P}<0.05$.

\section{Results}

The FTIR spectra of retina were obtained for normal and injected animals with different doses of $\mathrm{NaIO}_{3}$ with or without treated by taurine after one day. The spectra covering the range of 4000$900 \mathrm{~cm}^{-1}$ were recorded. Figure (1) summarized all overlaid FTIR spectra of all groups compared to normal spectra for animals decapitated after 1 day. Panel (a) of Fig. (1) shows all vibrational frequency range corresponding to retinal tissue of control group and the groups injected with 25, 50 and $75 \mathrm{mg}$ of $\mathrm{NaIO}_{3}$. Panel (b) shows overlaid FTIR spectra of normal rats retina and those of $4 \mathrm{~g}$ taurine supplement $/ 100 \mathrm{~g}$, diet two weeks before intravenous injection of $\mathrm{NaIO}_{3}$ which continued until decapitation after 1 day compared to control. 


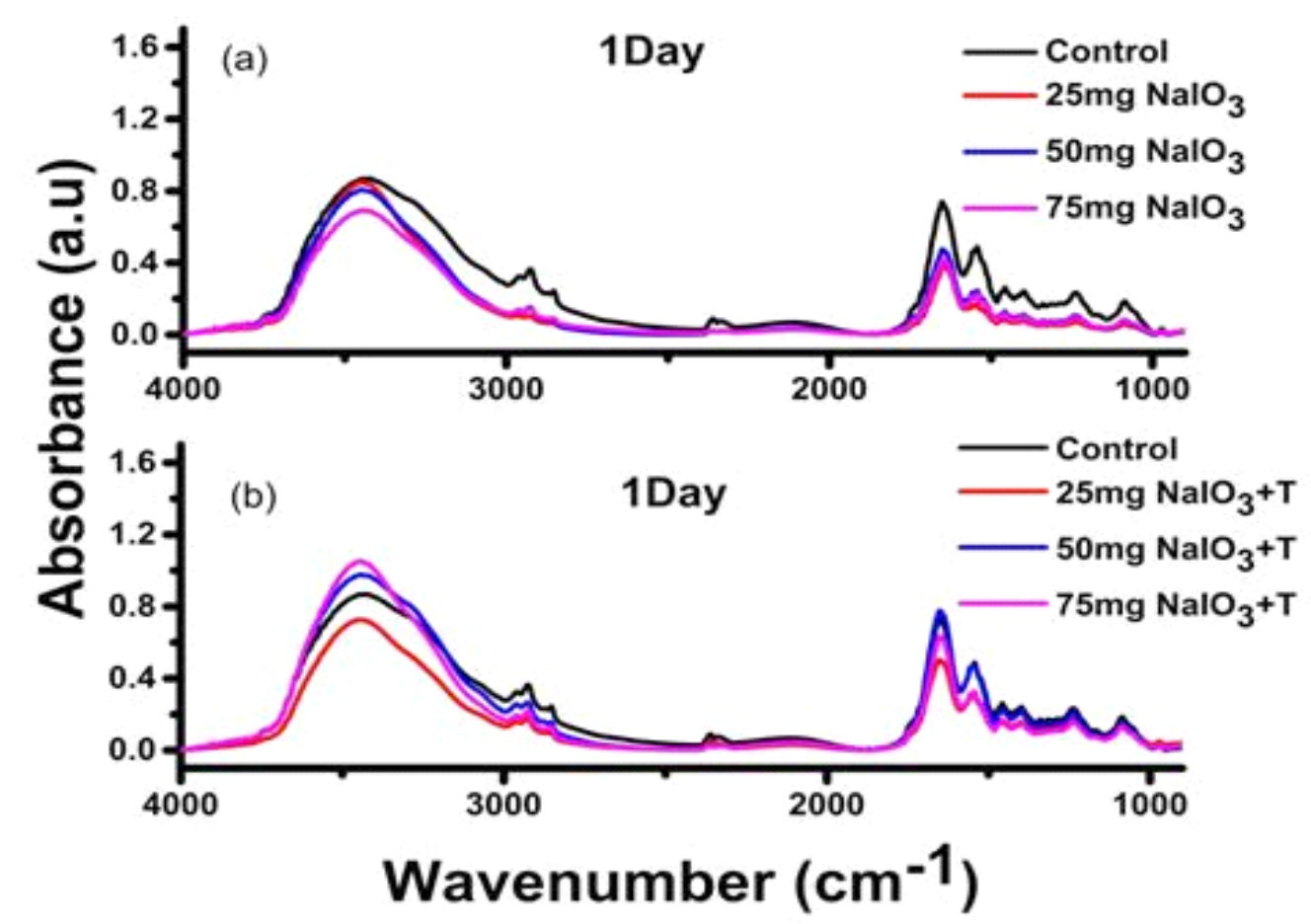

Fig. 1. FTIR spectra for rats injected with different doses of NaIO3(a) and rats supplemented with taurine before and after same doses of $\mathrm{NaIO3}$ (b) after one day.

The detailed spectral analyses are performed in 3 distinct wavenumber ranges; 4000-3000 $\mathrm{cm}^{-1}$ (NH-OH region), 3000-2800 $\mathrm{cm}^{-1}$ (C-H stretching region) and $1500-900 \mathrm{~cm}^{-1}$ (Fingerprint region). The amide I band that appears at $1650 \mathrm{~cm}^{-1}$ was measured separately since it consists of a number of underlying bands which corresponding to different protein secondary structural components.

\section{$\mathrm{NH}-\mathrm{OH}$ Region}

Figure (2) shows the $\mathrm{NH}-\mathrm{OH}$ region of the retinal FTIR spectra that has the range 4000$3000 \mathrm{~cm}^{-1}$, for control rats, rats injected with different doses of $\mathrm{NaIO}_{3}(25,50$ and $75 \mathrm{mg})$ and rats taurine supplement before and after injection of $\mathrm{NaIO}_{3}$ then decapitated after 1 day. The main band of the normal pattern is found at $3454 \pm 2 \mathrm{~cm}^{-1}$. The curve enhancement procedure resolved this band into 4 structural components (Table 1) correspond to (1) stretching $\mathrm{O}-\mathrm{H}$ $\left({ }_{\mathrm{str}} \mathrm{OH}\right),(2)$ asymmetric $\mathrm{O}-\mathrm{H} \quad\left({ }_{\text {asym }} \mathrm{OH}\right)$, (3) symmetric $\mathrm{O}-\mathrm{H}\left({ }_{\text {sym }} \mathrm{OH}\right)$ and (4) asymmetric $\mathrm{NH}_{3}\left({ }_{\text {asym }} \mathrm{NH}_{3}\right)$ respectively as assignments previously mentioned by Dovbeshko et al., ${ }^{(17)}$. Stretching O-H component vibrates in 3 modes of vibration.
Table (1) indicates the changes in vibrational frequency and the width in all bands in the NH-OH region after 1 day. For all groups injected with $\mathrm{NaIO}_{3}$ the 3 modes of vibrations related to $\mathrm{OH}$ appered at wave length $3740 \pm 2,3615 \pm 3,3532 \pm 2 \mathrm{~cm}^{-1}$ which observed in control pattern are decreased to one vibration mode and changed to a range between $3585 \pm 3$ to $3580 \pm 3 \mathrm{~cm}^{-1}$. In the same context, appear of 2 modes of vibrations for ${ }_{\text {str }} \mathrm{OH}$ to all groups taurine supplemented two weeks before intravenous injection of $\mathrm{NaIO}_{3}$ then continued until capitation after 1 day. There are statistically significant increments $(\mathrm{p}<0.05)$ in modes of vibration of $\mathrm{OH}$ and width in all doses injected of $\mathrm{NaIO}_{3}$ in contrast to ${ }_{\text {asym }} \mathrm{OH}$ vibration modes in taurine supplemented groups that had no significant differences in frequency and width compared to control. Mode of vibration related to ${ }_{\text {sym }} \mathrm{OH}$ suffered from statistically significant increases $(p<0.05)$ in width for $\mathrm{NaIO}_{3}$ groups. Also disappear of asym $\mathrm{NH}_{3}$ in $\mathrm{NaIO}_{3}$ groups and appear in taurine treated groups injected with 25 and $50 \mathrm{gm}$ of $\mathrm{NaIO}_{3}$. 


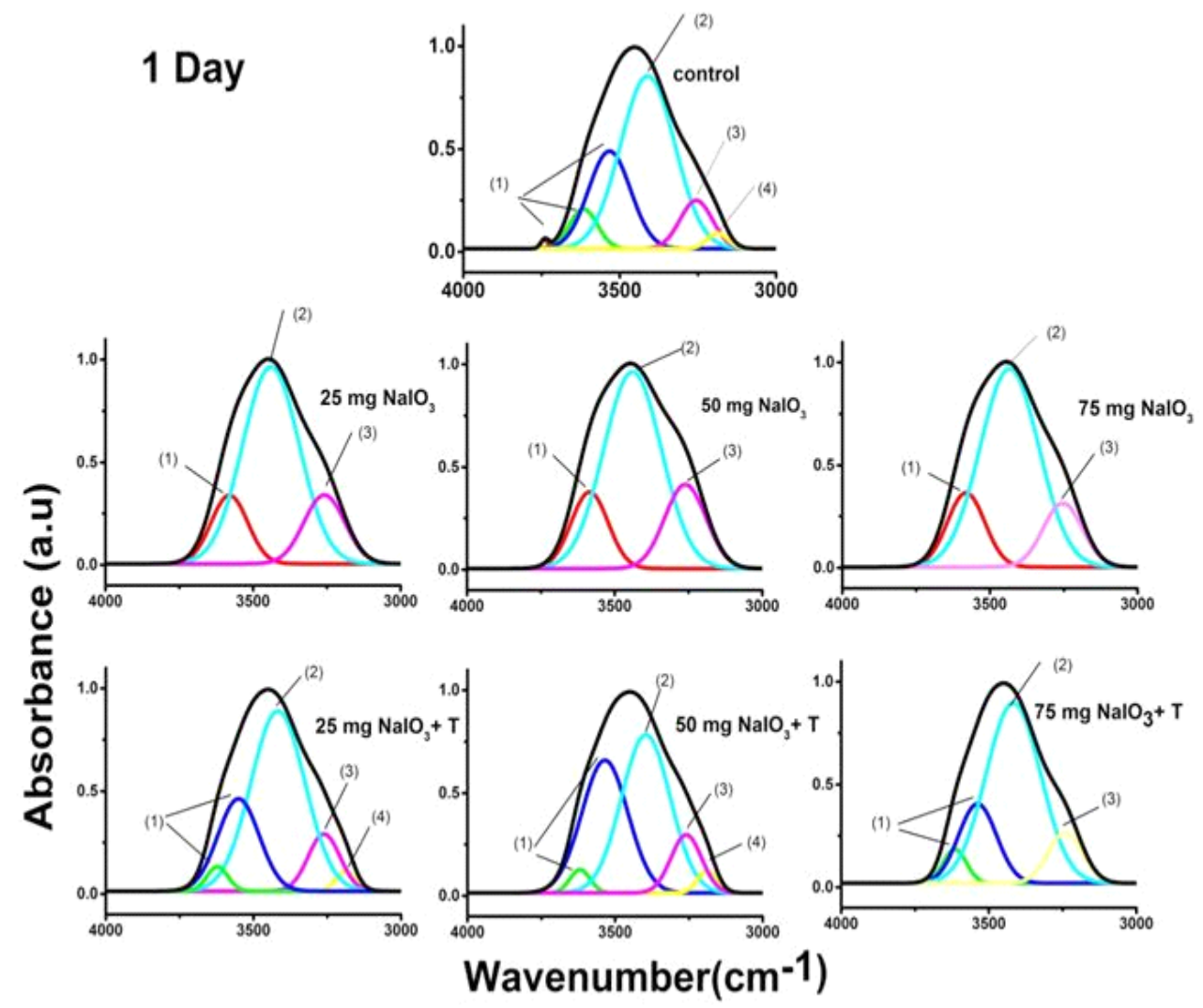

Fig.2.NH-OH region of the retinal FTIR spectra in the range $4000-3000 \mathrm{~cm}-1$ for control rats, rats injected with different doses of $\mathrm{NaIO} 3(25,50$ and $75 \mathrm{mg})$ and rats supplemented taurine before and after injection of NaIO3 after 1 day. (1) strOH, (2)asymOH,, (3) symOH and (4) sym NH3.

TABLE 1. Fourier deconvolution and nonlinear curve fitting of the NH-OH region of retina from normal and different groups of decapitated animals after 1 day.

\begin{tabular}{|c|c|c|c|c|c|c|c|}
\hline & & & & & $\underset{\text { asym }}{(2)}$ OH & $\begin{array}{c}\text { (3) } \\
\text { sym }\end{array}$ & $\underset{\text { sym }}{(\mathbf{N H}}$ \\
\hline Control & $3740 \pm 2$ & $3615 \pm 3$ & $3532 \pm 2$ & & $3408 \pm 4$ & $3256 \pm 3$ & $3187 \pm 2$ \\
\hline Coiritor & $30 \pm 1$ & $105 \pm 5$ & $158 \pm 4$ & & $204 \pm 6$ & $121 \pm 8$ & $79 \pm 7$ \\
\hline $25 \mathrm{mg} \mathrm{\textrm {NaIO } _ { 3 }}$ & & & & $3580 \pm 3$ & $3439 \pm 1 \dagger$ & $3258 \pm 3$ & \\
\hline & & & & $145 \pm 5$ & $226 \pm 3 \dagger$ & $162 \pm 3 \dagger$ & \\
\hline $50 \mathrm{mg} \underline{\mathrm{NaIO}}_{3}$ & & & & $3585 \pm 3$ & $3439 \pm 2 \dagger$ & $3260 \pm 3$ & \\
\hline & & & & $147 \pm 5$ & $230 \pm 4 \dagger$ & $164 \pm 3 \dagger$ & \\
\hline $75 \mathrm{mg} \underline{\mathrm{NaIO}}_{3}$ & & & & $3581 \pm 2$ & $3434 \pm 2 \dagger$ & $3253 \pm 2$ & \\
\hline & & & & $149 \pm 5$ & $234 \pm 4 \dagger$ & $156 \pm 3 \dagger$ & \\
\hline $25 \mathrm{mg} \underline{\mathrm{NaIO}}_{3}+\mathrm{T}$ & & $3620 \pm 2$ & $3551 \pm 3 \dagger$ & & $3413 \pm 4$ & $3260 \pm 2$ & $3188 \pm 2$ \\
\hline & & $85 \pm 2 \dagger$ & $164 \pm 8$ & & $215 \pm 7$ & $127 \pm 8$ & $78 \pm 5$ \\
\hline $50 \mathrm{mg} \underline{\mathrm{NaIO}}_{\underline{3}}+\mathrm{T}$ & & $3618 \pm 1$ & $3535 \pm 2$ & & $3403 \pm 3$ & $3258 \pm 3$ & $3188 \pm 2$ \\
\hline & & $81 \pm 4 \dagger$ & $173 \pm 4 \dagger$ & & $194 \pm 5$ & $122 \pm 8$ & $78 \pm 6$ \\
\hline $75 \mathrm{mg} \underline{\mathrm{NaIO}}_{3}+\mathrm{T}$ & & $3615 \pm 2$ & $3536 \pm 3$ & & $3413 \pm 2$ & $3250 \pm 3$ & \\
\hline & & $92 \pm 2 \dagger$ & $151 \pm 5$ & & $218 \pm 7$ & $137 \pm 8$ & \\
\hline
\end{tabular}

width, †Statistically significant

Egypt. J. Biophys. Biomed. Engng. Vol. 19 (2018) 


\section{C-H Region}

The infrared absorption pattern of control retina that is shown in Fig (3) compared to different groups studied after 1 day. The control pattern is characterized by 3 absorption bands in the IR range $3000-2800 \mathrm{~cm}^{-1}$. The curve enhancement procedure that used to resolve any overlapping peaks confirms the presence of four bands that are centered at $2960 \pm 2 \mathrm{~cm}^{-1}$ with bandwidth of $21 \pm 1 \mathrm{~cm}^{-1}, 2925 \pm 2 \mathrm{~cm}^{-1}$ with bandwidth of
$31 \pm 1 \mathrm{~cm}^{-1}, 2874 \pm 3$ with band width $46 \pm 2$ and $2852 \pm 2 \mathrm{~cm}^{-1}$ with corresponding bandwidth of $14 \pm 1 \mathrm{~cm}^{-1}$. These bands can be assigned as $\mathrm{CH}_{3 \text { asym }}, \mathrm{CH}_{2 \text { asym }}, \mathrm{CH}_{3 \text { sym }}$ and $\mathrm{CH}_{2 \text { sym }}$ respectively as shown in Table (2). The assignment of the bands has been previously mentioned by Severcan et al., ${ }^{(18)}$. As observed from their assigned, there are no significant changes in band absorbance or band width to all groups compared to control.

\section{1 day}
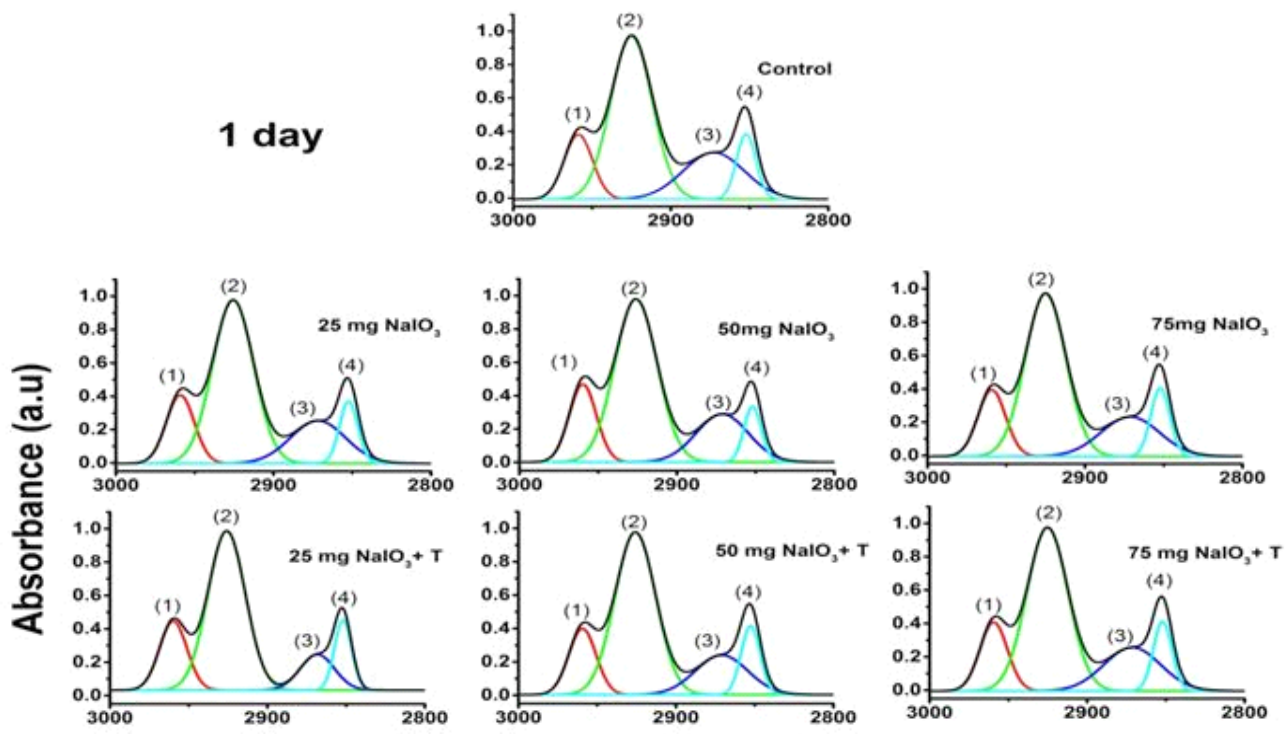

Wavenumber $\left(\mathrm{cm}^{-1}\right)$

Fig. 3. CH region of retina from normal group, animals injected with NaIO3 and treated by taurine after 1 day showing the deconvoluted FTIR spectrum.(1) asym CH3, (2) asym CH2,(3) sym CH3 and (4) sym CH2.

TABLE 2. Estimated structural components with its vibrational frequencies, bandwidth and area of the $\mathrm{CH}$ region of retina for normal, different doses of $\underline{\mathrm{NaIO}}_{3}$ injection and treated with taurine before and after injection after 1 day.

\begin{tabular}{|c|c|c|c|c|}
\hline & (1) $\mathrm{CH}_{3 \text { asym }}$ & (2) $\mathrm{CH}_{2 \text { asym }}$ & (3) $\mathrm{CH}_{3 \mathrm{sym}}$ & (4) $\mathrm{CH}_{2 \text { sym }}$ \\
\hline \multirow{2}{*}{ Control } & $2960 \pm 2$ & $2925 \pm 2$ & $2874 \pm 3$ & $2852 \pm 2$ \\
\hline & $21 \pm 1$ & $31 \pm 1$ & $46 \pm 2$ & $14 \pm 1$ \\
\hline \multirow{2}{*}{$25 \mathrm{mg} \underline{\mathrm{NaIO}}_{\underline{3}}$} & $2960 \pm 1$ & $2926 \pm 2$ & $2872 \pm 2$ & $2852 \pm 1$ \\
\hline & $21 \pm 1$ & $31 \pm 1$ & $39 \pm 2 \dagger$ & $14 \pm 1$ \\
\hline \multirow{2}{*}{$50 \mathrm{mg} \underline{\mathrm{NaIO}}_{\underline{3}}$} & $2960 \pm 3$ & $2926 \pm 4$ & $2871 \pm 4$ & $2852 \pm 3$ \\
\hline & $20 \pm 1$ & $32 \pm 1$ & $39 \pm 1 \dagger$ & $13 \pm 2$ \\
\hline \multirow{2}{*}{$75 \mathrm{mg} \underline{\mathrm{NaIO}}_{\underline{3}}$} & $2959 \pm 2$ & $2925 \pm 2$ & $2871 \pm 2$ & $2852 \pm 4$ \\
\hline & $21 \pm 1$ & $30 \pm 1$ & $43 \pm 3$ & $14 \pm 2$ \\
\hline \multirow[t]{2}{*}{$25 \mathrm{mg} \underline{\mathrm{NaIO}}_{\underline{3}}+\mathrm{T}$} & $2960 \pm 3$ & $2926 \pm 3$ & $2868 \pm 4$ & $2852 \pm 2$ \\
\hline & $21 \pm 2$ & $28 \pm 2$ & $41 \pm 3$ & $13 \pm 1$ \\
\hline \multirow{2}{*}{$50 \mathrm{mg} \underline{\mathrm{NaIO}}_{\underline{3}}+\mathrm{T}$} & $2959 \pm 1$ & $2926 \pm 2$ & $2870 \pm 3$ & $2853 \pm 2$ \\
\hline & $20 \pm 1$ & $30 \pm 2$ & $41 \pm 2$ & $14 \pm 2$ \\
\hline \multirow[t]{2}{*}{$75 \mathrm{mg} \underline{\mathrm{NaIO}}_{\underline{3}}+\mathrm{T}$} & $2959 \pm 4$ & $2925 \pm 2$ & $2871 \pm 2$ & $2852 \pm 3$ \\
\hline & $21 \pm 1$ & $31 \pm 2$ & $42 \pm 3$ & $14 \pm 1$ \\
\hline
\end{tabular}

First line in each cell indicates the vibrational frequency in $\mathrm{cm}^{-1} \pm$ standard deviation, while second line reflect the bandwidth. 


\section{Fingerprint Region}

Figure (4) shows the FTIR absorption spectra in the range $1600-900 \mathrm{~cm}^{-1}$ for control group, animals injected with $\mathrm{NaIO}_{3}(25,50$ and 75 $\mathrm{mg}$ ) after one day and those which are taurine supplemented before and after injection of $\mathrm{NaIO}_{3}$. This figure shows the presence of eleven bands in the normal pattern, that are centered at $1542 \pm 2 \mathrm{~cm}^{-1}$ and $1521 \pm 1$ (amide II $\mathrm{N}=\mathrm{H}_{\text {bend }}$ ), $1457 \pm 4 \mathrm{~cm}^{-1}$ ( $\left.{ }_{\text {bend }} \mathrm{CH}_{2}\right), 1399 \pm 5 \mathrm{~cm}^{-1}\left(\mathrm{COO}_{\text {str }}^{-}{ }_{\text {sym }}\right)$, $1337 \pm 3 \mathrm{~cm}^{-1}$ and $1315 \pm 3 \mathrm{~cm}^{-1}\left(\mathrm{CH}_{3 \mathrm{def}}\right.$ deformation), $1284 \pm 3 \mathrm{~cm}^{-1}$ and $\quad 1233 \pm 2 \mathrm{~cm}^{-1} \quad\left(\mathrm{sO}_{2}^{-} \mathrm{PO}_{\text {asym }}^{-}\right)$, $1167 \pm 2 \mathrm{~cm}^{-1} \quad\left(\mathrm{COOC}_{\text {str }}\right), 1085 \pm 4,\left(\mathrm{str}_{\mathrm{str}} \mathrm{PO}_{2}{ }_{\text {sym }}\right)$ and $1052 \pm 3 \mathrm{~cm}^{-1}\left({ }_{\text {str }} \mathrm{COC}\right)$ as shown in table (3). The bands assignments have been indicated by Jung. (19) The most obvious observation due to $\mathrm{NaIO}_{3}$ injection is disappearance in mode of vibration related to Amide II that appeared in control and the re-appearance in all groups treated with taurine. Some fluctuation observed in number of modes of vibrations related to ${ }_{\text {str }} \mathrm{PO}_{2}^{-}$asym, ${ }_{\text {str }} \mathrm{COOC}_{\text {asym }}$ and ${ }_{\text {str }} \mathrm{COC}$ in a way that cannot be attributed to $\mathrm{NaIO}_{3}$ injection or taurine treated as indicated in Table (3).

\section{Amide I band}

Analysis of the amide I band Fig.(5) shows the curve enhancement procedure to control group, animal groups injected with 25,50 and $75 \mathrm{mg}$ of
$\mathrm{NaIO}_{3}$ and groups treated with taurine after 1 day. The analysis resolved the contour of the normal band into 3 compositional bands that are centered at $16732 \mathrm{~cm}^{-1}$ ( $\beta$-Turns), $16481 \mathrm{~cm}^{-1}(\alpha$-helix), and $16271 \mathrm{~cm}^{-1}$ ( $\beta$-Sheet) (Lin et al., 1998). Table (4) indicates that the distribution of normal protein secondary structure components - that are calculated as the area percentage - are the following; $192 \%$ for $\beta$-Turns, $604 \%$ for $\alpha$-helix and $202 \%$ for $\beta$-Sheet. The assignment of the bands are indicated by Fuller et al., ${ }^{(20)}$. After 25, 50 and $75 \mathrm{mg}$ of $\mathrm{NaIO}_{3}$ injection, the number of estimated bands were increased to 4, 5 and 6 bands respectively. For all doses of $\mathrm{NaIO}_{3}$ injection, there are statistically significant decrements $(p<0.05)$ in $\alpha$-helix associated with statistically significant increases $(\mathrm{p}<0.05)$ in $\beta$-Sheet structures. By taurine treatment before and after injection of $25 \mathrm{mg}$ of $\mathrm{NaIO}_{3}$, the number of estimated peaks returned back to the control pattern of 3 peaks and no significant differences appeared in $\alpha$-helix content or $\beta$-Sheet structures. However, after high doses of $\mathrm{NaIO}_{3}$ (50 and $75 \mathrm{mg}$ ) the number of peaks related to the protein structure components became 5 and 6 respectively and statistically significant diminish $(\mathrm{p}<0.05)$ in $\alpha$-helix associated with statistically significant increment $(\mathrm{p}<0.05)$ in $\beta$-Sheet structures were observed.

1 Day

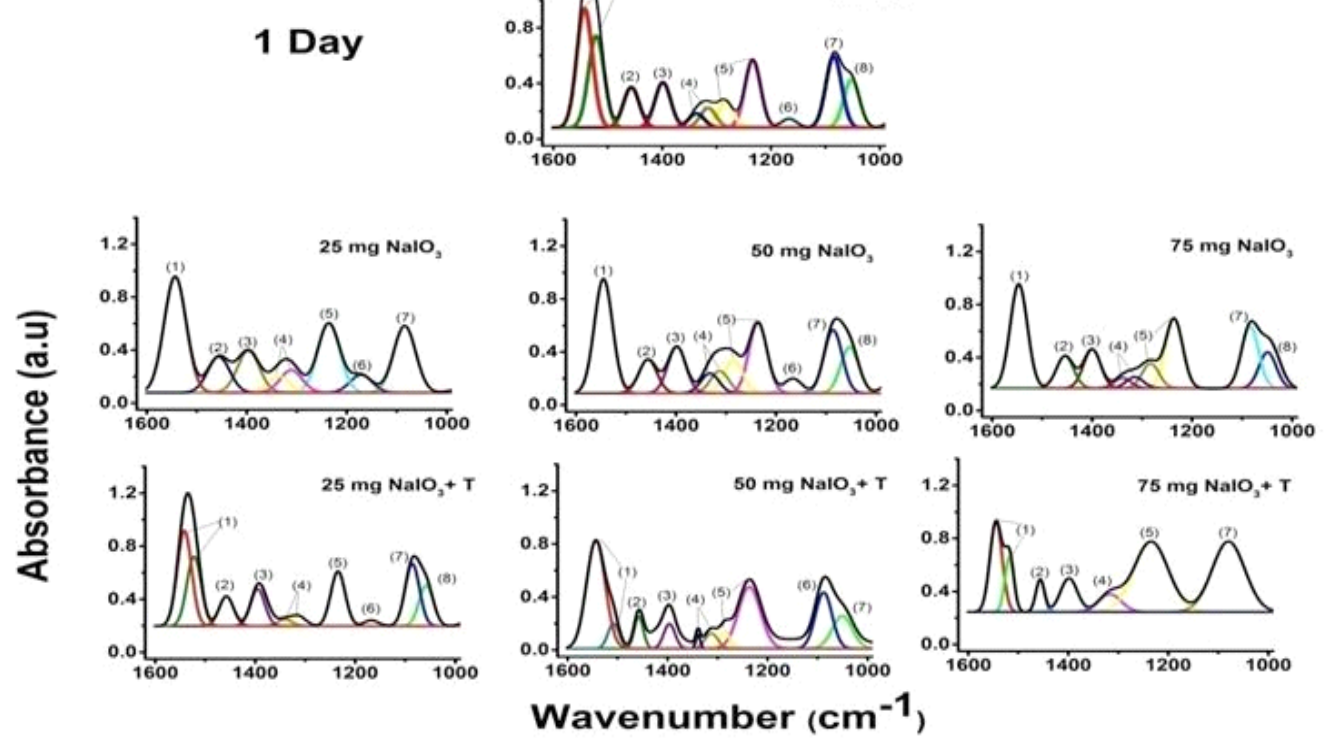

Fig.4. FTIR spectra of the fingerprint region of all groups compared to control. The numbers above the peaks are to facilitate their assignment. (1) Amide II, (2) $\mathrm{CH}_{2}$ bend ,(3) strCOO${ }^{-}$sym , (4) $\mathrm{CH}_{3} d e f$, (5) strPO2 ${ }^{-}$asym , (6) strCOOCasym, (7) strPO2 ${ }^{-}$sym and (8) strCOC.

Egypt. J. Biophys. Biomed. Engng. Vol. 19 (2018) 


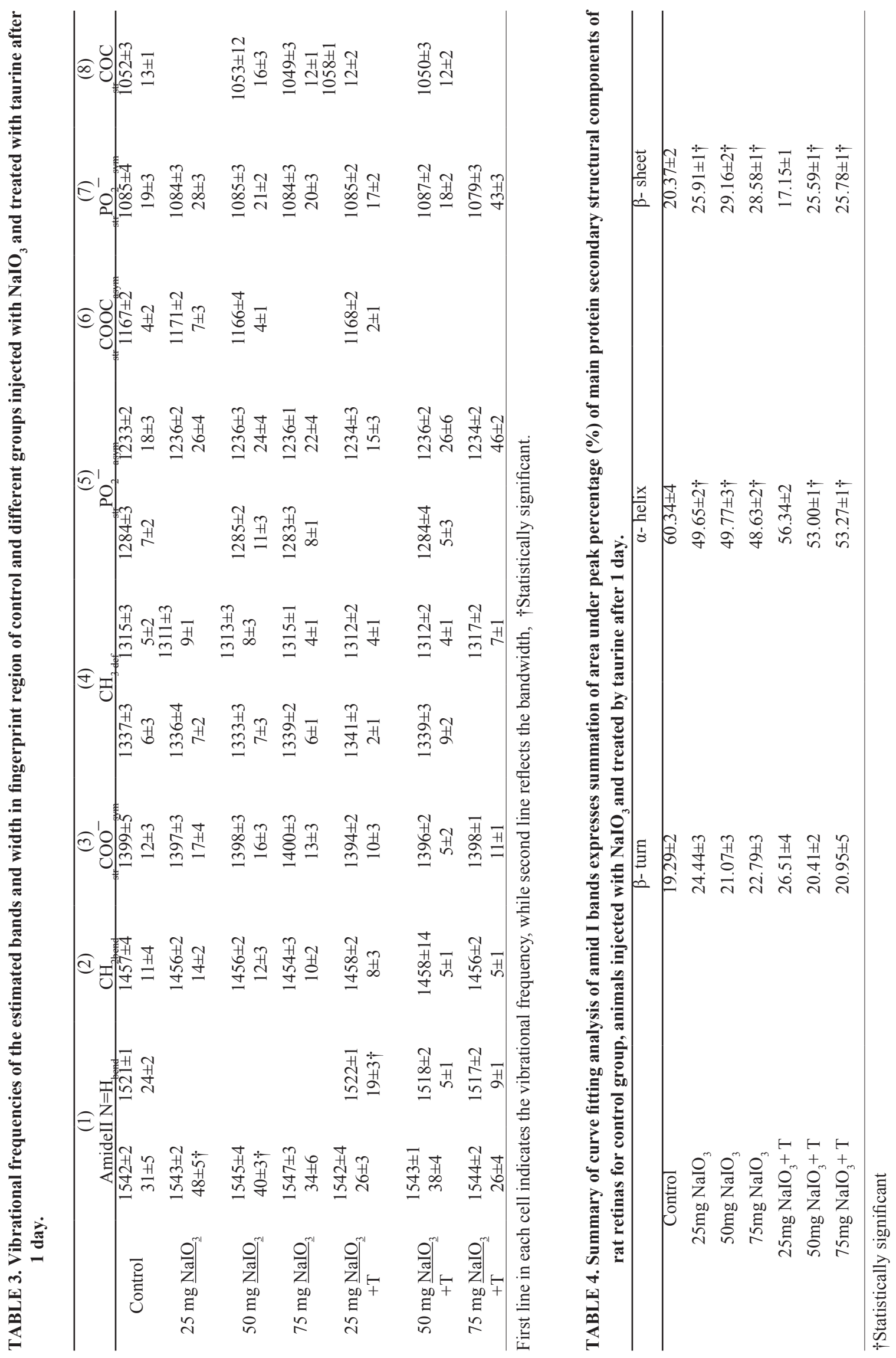




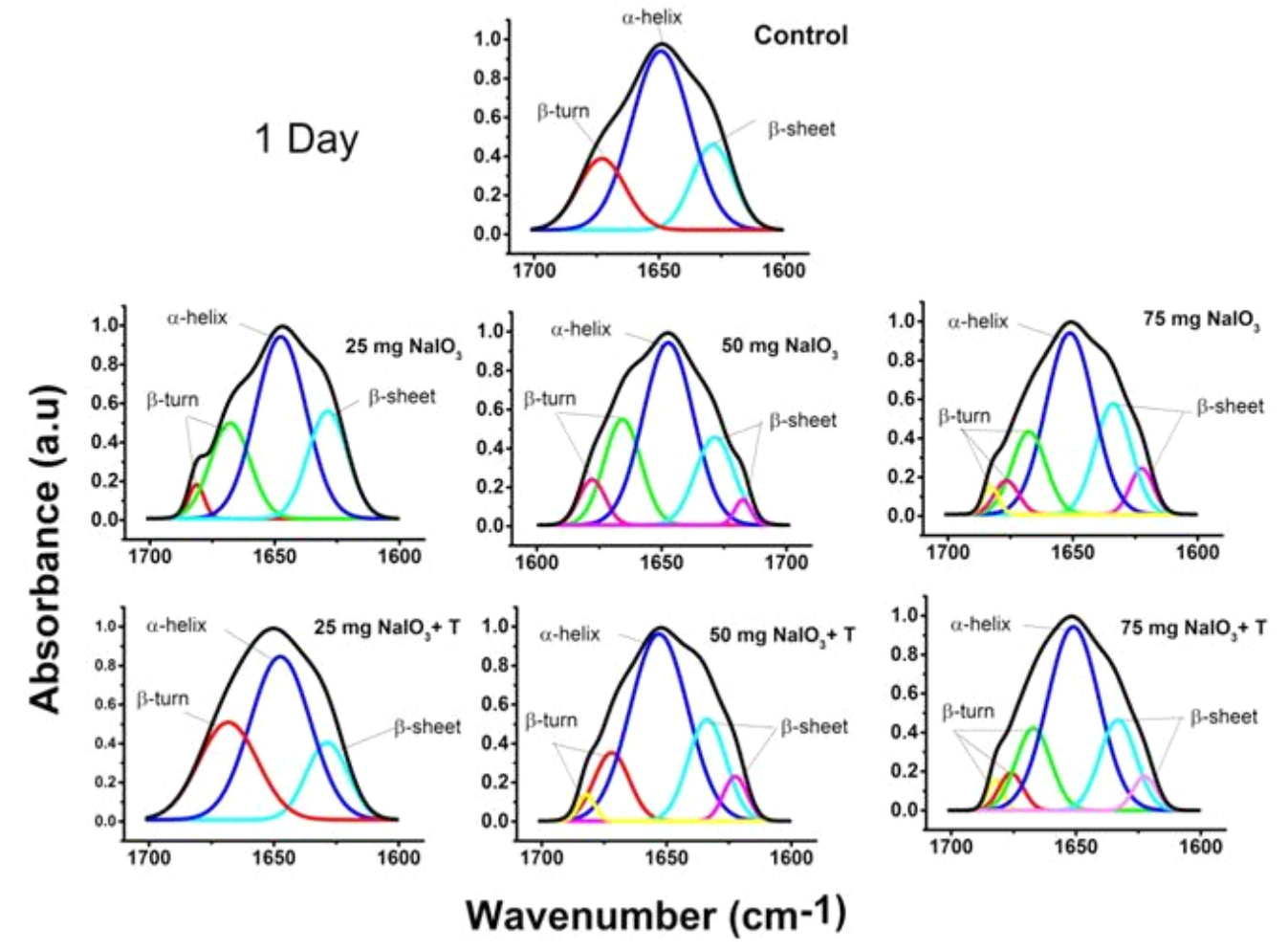

Fig. 5. Amide I region (1700:1600 cm-1) of deconvoluted FTIR spectrum to retina for control group, animals injected with $\mathrm{NaIO3}$ and treated by taurine after 1 day.

\section{Discussion}

This study reveals that $\mathrm{NH}-\mathrm{OH}$ region is affected by injection of $\mathrm{NaIO}_{3}$ where there is a different interaction/binding mechanism and production of various states in the retinal system, as well as different configurations and conformations co-exist in the system. There are changes in modes and the number of vibration for ${ }_{\text {str }} \mathrm{OH}$ are related to $\mathrm{NaIO}_{3}$ injection, The observed recovery is connected to taurine treatment and it appears to be dose dependent. In addition, the disappearance of ${ }_{\text {sym }} \mathrm{NH}_{3}$ in all $\mathrm{NaIO}_{3}$ injected groups reflect changes in membrane structure of retinal cells since NH bond exists in several membrane constituents that contain protein and lipid. These changes are in line with the work by Aboualizadeh et al., 2015 (21) who observed changes in FTIR spectra of retinal cells due to oxidative stress. The appearance of ${ }_{\text {sym }} \mathrm{NH}_{3}$ in most taurine treated groups indicates the recovery following the taurine treatment. Also, $\mathrm{NaIO}_{3}$ injection enhances the asymmetric vibrational motion of the $\mathrm{OH}$ band which may be indicative for different types of membrane disorder. The observed positive effect exerted by taurine could be ascribed to its ability to induce more vibrational motion in the taurine treated groups ( 25,50,75 mg of $\mathrm{NaIO}_{3}$ ) compared to control. Analysis of fingerprint region is concerning with the changes in the amide II band vibration mode, due to coupling of $\mathrm{CN}$ stretching and in-plane bending of the $\mathrm{N}-\mathrm{H}$ group. The decrease of amide II vibration modes in all groups of $\mathrm{NaIO}_{3}$ injection groups revealed its action. The appearance or disappearance of modes of vibration infrared bands may be due carbonization, degeneration of biological tissues and losing its function that is in agreement with Zezell et al., 2015 ${ }^{(22)}$ and lor transcriptional regulation effect as observed by Lima et al., 2015 (23). However, the amide II band is not often used for structural studies because it is less sensitive and subject to interference from absorption bands of amino acid side-chain vibrations as described by Al-Muslet and Ali $2012^{(24)}$. The noticeable fluctuation changes in the fingerprint region recognized to the oxidative 
stress after injection of all doses of $\mathrm{NaIO}_{3}$ leading to increase the stress with the dose which is consistent with the work of Zhang et al., 2016 (25) that suggested accumulation of reactive oxygen species in retina due to injection of $\mathrm{NaIO}_{3}$ and resemble condition of AMD.

The protein secondary structure is affected by all doses of $\mathrm{NaIO}_{3}$ injection where a change in the $\alpha$-helix, $\beta$-sheet and $\beta$-turn contents is observed. It has been suggested by Mitra et al., $2017^{(26)}$ that protein insolubility depends on the content of the $\beta$-sheet structure: more $\beta$-sheet structure means more insoluble protein that agree with our results in decrease $\alpha$-helix, and the disordered chains aggregate to form $\beta$-sheet structure. Changes in the profile and the pattern of the amide I band are clearly observed for all $\mathrm{NaIO}_{3}$ groups compared with the control pattern. These changes in the amide I band profile are due to differences in hydrogen-bonding strengths, differences in transition dipole coupling and consequently in molecular geometry of proteins, which may induce damages in protein folding and result in definitive loss of protein biological function as these are the factors that give the amide I band its sensitivity to protein secondary conformational changes. These findings are in line with the results of study by Zhou et al.,2014(1) who reported that the molecular mechanism of RPE damage that occurs after $\mathrm{NaIO}_{3}$ administration is thought to be mediated through induction of oxidative stress through accumulation of ROS that co-localizes with mitochondria.

All changes observed in the pesented study may cause the retina to lose function. Such function loss could be due to two factors. First, $\mathrm{NaIO}_{3}$ treatment could cause synaptic damage, as a defect in synaptic transmission between the photoreceptors and depolarizing bipolar cells can lead to a weaken ERG b-wave as observed by Pang et al., $2006^{(27)}$. This idea is supported by Hariri $2013^{(28)}$ who used SD-OCT to describe early changes associated with injection of high doses of $\mathrm{NaIO}_{3}$ in rats and demonstrating a rapid swelling of photoreceptor outer segments due to hydropic change. Secondly, $\mathrm{NaIO}_{3}$ could directly alter photoreceptor function and cell survival with a special stress on oxidative stress leading to phototransduction processes changes as reported by Wang et al., $2014^{(29)}$.

A complete recovery is observed in our study following the treatment with taurine before and after the $25 \mathrm{mg}$ of $\mathrm{NaIO}_{3}$ injection and a partial role with the 50 and , $75 \mathrm{mg}$ of injection. The effect of taurine is correlated to its antioxidative activity as confirmed by Imaki et al. ${ }^{(30)}$, and Ishikawa et al., ${ }^{(31)}$. Dietary taurine is absorbed via the digestive system and then is transported by the $\mathrm{Na}^{+}$- dependent taurine transporter into the retina through the blood-retinal barrier. The role taurine may play in the retina is the promotion of retinal cell differentiation during rod photoreceptor development ${ }^{(32)}$.

Various physiological roles have been suggested for taurine, among which are modulation of $\mathrm{Ca}{ }^{2+}$ transport, antioxidation, neurotransmission, osmoregulation, membrane stabilization, and regulation of protein phosphorylation. Many of the actions of taurine may be considered as membrane based, in which taurine is modify membrane phospholipids, thus modifying membrane function ${ }^{(33)}$.

\section{Conclusion}

- FTIR spectroscopy has been an integral part of understanding the mechanisms behind protein misfolding diseases including MDA

- $\mathrm{NaIO}_{3}$ is considered to be highly specific for animal model to AMD and oxidative stress to retina even in low dose.

- Taurine is required for maintaining retinal health since it fights oxidative stress. Evidence is strong that taurine is vital in maintaining optimal retinal function .Taurine action is appeared in range of 25 $\mathrm{mg}$ of $\mathrm{NaIO}_{3}$ and decrease the efficiency by increasing the dose of $\mathrm{NaIO}_{3}$ to $75 \mathrm{mg}$.

\section{References}

Zhou, P., Kannan, R., Spee, C., Sreekumar, P.G., Dou, G., et al. Protection of Retina by aB Crystallin in Sodium Iodate Induced Retinal Degeneration. PLoS ONE 9(5), e98275 (2014).

Zengin, M.O., Karti, O., Karahan, E., Kusbeci, T., An Evaluation of the Relationship Between Clinically Unilateral Pseudoexfoliation Syndrome and AgeRelated Macular Degeneration. Ophthalmic Surg Lasers Imaging Retina. Jan 1; 49(1),12-19(2018).

Coleman, H.R., Chan, C.C., Ferris, F.L., 3rd, Chew, E.Y., Age-related macular degeneration. Lancet. 372(9652), 1835-1845(2008). 
Pinazo-Durán, M.D., Gómez-Ulla, F., Arias, L., et al., Do Nutritional Supplements Have a Role in Age Macular Degeneration Prevention? Journal of Ophthalmology. 2014:901686(2014).

Wang, J., Lacovelli, J., Spencer, C., Saint-Geniez, M., New insights on sodium iodate-induced retianl degeneration. FASEB J 27: Suppl 873.15(2013).

Zulliger, R., Cellular and molecular changes in animal models of retinal degeneration $[\mathrm{PhD}]$ : University of Bern (2010).

Korte, G.E., Reppucci, V., Henkind, P., RPE destruction causes choriocapillary atrophy. Invest Ophthalmol Vis Sci. 25, 1135-1145(1984).

Hanus, J., Anderson, C., Sarraf, D., Ma, J., \& Wang, S., Retinal pigment epithelial cell necroptosis in response to sodium iodate. Cell Death Discovery, 2, 16054-(2016).

Das, J., Sil, P.C., Taurine ameliorates alloxan-induced diabetic renal injury, oxidative stress-related signaling pathways and apoptosis in rats. $\underline{\text { Amino }}$ Acids. Oct; 43(4), 1509-23(2012).

Perfeito, R., Cunha-Oliveira, T., Rego, A.C., Revisiting oxidative stress and mitochondrial dysfunction in the pathogenesis of Parkinson disease--resemblance to the effect of amphetamine drugs of abuse. Free Radic Biol Med. Nov 1; 53(9),1791-806(2012).

Chen, G., Nan, C., Tian, J., Jean-Charles, P, Li, Y., Weissbach, H., Huang, X.P., Protective effects of taurine against oxidative stress in the heart of MsrA knockout mice. J Cell Biochem.113:3559-66 (2012).

Marcinkiewicz, J., Kontny, E., Taurine and inflammatory diseases. Amino Acids. Jan; 46(1), 7-20(2014).

Jong, C.J., Azuma, J., Schaffer, S., Mechanism underlying the antioxidant activity of taurine: prevention of mitochondrial oxidant production. Amino Acids.42,2223-32(2012).

Yang, Y., Tsz, Kin, N.g., and Cong, Y.e., Assessing Sodium Iodate-Induced Outer Retinal Changes in Rats Using Confocal Scanning Laser Ophthalmoscopy and Optical Coherence Tomography. Invest. Ophthalmol. Vis. Sci. March 20(55) no. 3, 1696-1705(2014).

Eman, M.A., Mervat, A.A., and Eman, S. M., Attenuation of retinal damage after exposure to white light by taurine assessed by electroretinogram and comet assay. Int J Pharm Bio Sci Oct; 3(4),(B) 1109 - 1119 (2012).

Egypt. J. Biophys. Biomed. Engng. Vol. 19 (2018)
Sherif, M.S., Mervat, A.A., Eman, A.M., Infrared spectroscopic investigation of erythrocyte membrane-smoke interactions due to chronic cigarette smoking. Gen Physiol Biophys. Jul; 36(3), 273-280 (2017).

Dovbeshko, G.I., Gridina, N.Y., Kruglova, E.B. and O.P. Pashchuk, FTIR spectroscopy studies of nucleic acid damage, Talanta. 53, 233-246 (2000).

Severcan, F., Toyran, N., Kaptan, N. and B. Turan, Fourier transform infrared study of the effect of diabetes on rat liver and heart tissues in the $\mathrm{C}-\mathrm{H}$ region, Talanta, 53(1), 55-59(2000).

Jung, C., Review Insight into protein structure and protein-ligand recognition by Fourier transform infrared spectroscopy, Journal of Molecular Recognition, 13, 325-351(2000).

Fuller, A.A., Du, D., Liu, F., Davoren, J., Bhabha, G. and g. Kroon, et al., Evaluating -turn mimics as sheet fold nucleators, PNAS, 106, 11067-11072 (2009).

Aboualizadeh E, Ranji M, Sorenson CM, Sepehr R, Sheibani N, Hirschmugl CJ. Retinal oxidative stress at the onset of diabetes determined by synchrotron FTIR widefield imaging: towards diabetes pathogenesis. Analyst. Mar 27; 142(7), 1061-1072 (2017)

Zezell, D.M., Benetti, C., Veloso, M.N., Castro, A.A.P., and Ana, A.B., FTIR Spectroscopy Revealing the Effects of Laser and Ionizing Radiation on Biological Hard Tissues. J. Braz. Chem. Soc., 26(12), 2571-2582, 2015.

Lima, C.A., Goulart, V.P., Côrrea, L., Pereira, T.M., Zezell, D.M., ATR-FTIR spectroscopy for the assessment of biochemical changes in skin due to cutaneous squamous cell carcinoma. Int J Mol Sci. Mar 24;16(4),6621-30(2015).

Al-Muslet, N.A. \& Ali, E.E., Spectroscopic analysis of bladder cancer tissues using Fourier transform infrared spectroscopy J. Appl. Spectrosc. 79, 139(2012).

Zhang, X-Y, Ng TK, Brelén ME, et al. Continuous exposure to non-lethal doses of sodium iodate induces retinal pigment epithelial cell dysfunction. Sci Rep. 6, 37279 (2016).

Mitra, B., Rinnan, Å, Ruiz-Carrascal, J. Tracking hydrophobicity state, aggregation behaviour and structural modifications of pork proteins under the influence of assorted heat treatments. Food Res Int. Nov;101,266-273(2017) 
Pang, J.J., Abd-El-Barr, M.M., Gao, F., Bramblett, D.E., Paul, D.L., Wu, S.M., Relative contributions of rod and cone bipolar cell inputs to AII amacrine cell light responses in the mouse retina. J. Physiol. 580, 397-410(2006).

Hariri, S., Noninvasive imaging of the early effect of sodium iodate toxicity in a rat model of outer retina degeneration with spectral domain optical coherence tomography. J Biomed Opt. 18, 026017(2013).

Wang, J., Iacovelli, J., Spencer, C., Saint-Geniez, M., Direct effect of sodium iodate on neurosensory retina. Invest Ophthalmol Vis Sci. Mar 28; 55(3), 1941-53(2014).

Imaki, H., Neuringer, M., \& Sturman, J., Long-term effects on retina of rhesus monkeys fed taurine free human infant formula. Adv Exp Med Biol. 403, 351-360(1996).
Ishikawa, A., Shiono, T., Ishiguro, S., Tamai, M., Postnatal developmental expression of glutamine and related amino acids in the rat retinas. Curr Eye Res 15, 662-668(1996).

Militante, J., \& Lombardini, J.B., Age-related retinal degeneration in animal models of aging: possible involvement of taurine deficiency and oxidative stress. Neurochem Res 29, 151-160(2004).

Ma, N., Wang, S., Okita, S., Kato, T., Huang, S., Lu, C., Tsunekawa, M., Sasoh, M., Contribution of taurine signatures in the detached cat retina. Adv Exp Med Biol. 803,439-47(2015).

(Received $22 / 5 / 2018$;

accepted $23 / 9 / 2018$ ) 
التغيرات الجزيئية في بنية شبكية العين للجرذان بعدالعقن بأيودات الصوديوم وتأثير التورين محمد إسماعيل الجوهري 1 , إيمان محمد على ², أحمد السيد ملش2

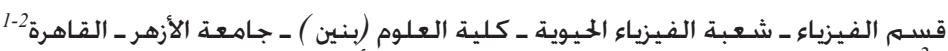
.

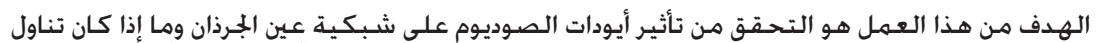

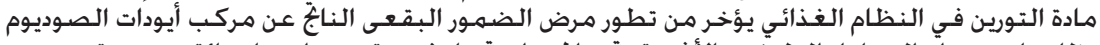

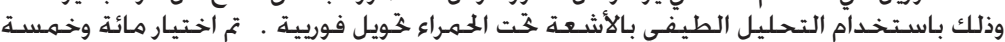

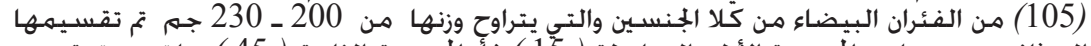

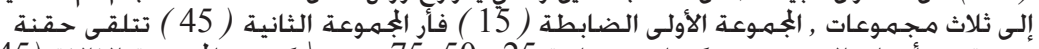

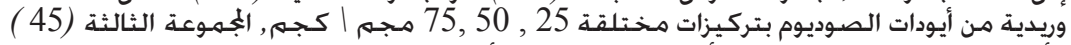

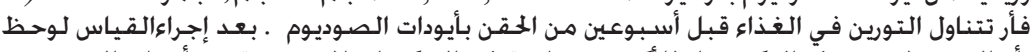

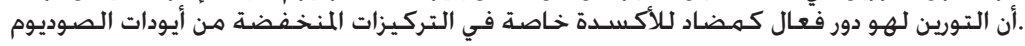

